\title{
Socioeconomic resources and quality of life in alcohol use disorder patients: the mediating effects of social support and depression
}

\author{
Soo Bi Lee', Sulki Chung ${ }^{1 *}$ (D, Jeong Seok Seo ${ }^{2}$, Won Mi Jung ${ }^{3}$ and II Ho Park ${ }^{4}$
}

\begin{abstract}
Background: Quality of life (QoL) has recently attracted increased attention as a major indicator of the recovery from alcohol use disorder (AUD). This study investigated the mediating effects of social support and depression for the relationship between socioeconomic resources and QoL among people with AUD in South Korea.

Methods: Patients across South Korea who had been diagnosed with AUD in the previous year $(n=404)$ and were registered at hospitals and addiction management centers were surveyed. The participants ranged in age from 19 to 65 years. Structural equation modeling was performed, using stable residence, income, stable employment, social support, depression, and QoL as predictors. Bootstrapping analysis was performed to test for mediating effects.

Results: The socioeconomic resources income $(\beta=.297, p<.001)$, stable employment $(\beta=.131, p<.01)$, and stable residence $(\beta=.091, p<.05)$ showed statistically significant and positive relationships with social support. However, none of these were significantly related to depression. Social support showed a significant and negative relationship with depression $(\beta=-.172, p<.001)$. Income positively and directly influenced $\mathrm{QoL}(\beta=.148, p<.001)$. All three socioeconomic resources indirectly influenced depression through social support, which, in turn, influenced QoL. This suggests that socioeconomic resources directly influence QoL and indirectly influence it through social support.

Conclusion: These findings suggest that social support has an important role in improving the QoL of people with AUD. Furthermore, socioeconomic resources, such as having a stable residence, employment, and income, are necessary for recovery from alcohol addiction.
\end{abstract}

Keywords: Alcohol use disorder, Depression, Quality of life, Social support, Socioeconomic resources

\section{Background}

The lifetime prevalence of alcohol use disorder (AUD) in South Korea is higher than that of many other diseases, at $12.2 \%$ for adults $(18.1 \%$ for males and $6.4 \%$ for females) [1]. As of 2016, among those diagnosed with mental illness, $40.4 \%$ were diagnosed with mood disorders, $32.1 \%$ with schizophrenia spectrum disorders, and $19.3 \%$ with anxiety disorders, but only $8.1 \%$ were diagnosed with AUD [1]. There are serious, harmful effects

\footnotetext{
* Correspondence: chungs@cau.ac.kr

'Department of Social Welfare, Chung-Ang University, 84 Heuksuk-Ro,

Dongjak-Gu, Seoul, South Korea

Full list of author information is available at the end of the article
}

on Korean society due to AUD, but only a small number of heavily dependent people access the limited treatment services. Public awareness of AUD in Korea is very low, and treatment efficiency and accessibility have been reduced due to trends in public perceptions regarding long-term treatment. Furthermore, the roles and functions of outpatient treatment and community mental health institutions as currently instituted are not sufficient for maintaining treatment and preventing relapse [2]. In addition, very few social rehabilitation services exist that can support recovery from AUD and successful reintegration [3].

(c) The Author(s). 2020 Open Access This article is distributed under the terms of the Creative Commons Attribution 4.0 International License (http://creativecommons.org/licenses/by/4.0/), which permits unrestricted use, distribution, and 
The damage caused by AUD goes beyond harms to health, including liver disease, diabetes, high blood pressure, cardiovascular disorders $[4,5]$, and mental illnesses such as depression and anxiety [6]: it also impairs quality of life (QoL) in sufferers in other ways, damaging interpersonal and social roles, and this makes recovery more difficult [7]. Recovery from AUD requires a comprehensive approach that takes into account biological, psychological, and socioeconomic factors $[8,9]$.

Although different researchers have presented a range of conceptions of recovery from AUD, it should be considered to be a continuous, stepwise process, going beyond symptomatic improvement alone [10]. According to the New Freedom Commission on Mental Health, recovery is a healthy and efficient process that enables and empowers people with addictions to live, work, learn, and freely engage in life [11]. For AUD, improvements in QoL are arguably the ultimate goal of treatment programs and their assessment should be recognized as a major focus of research on therapeutic outcomes [12, 13]. The concept of recovery from AUD has evolved from simple observed changes in drinking patterns or decreased alcohol consumption to larger picture of overall improvements in health, relationships, and QoL [1417]. The recovery of people with AUD in relation to QoL can be understood as a process of repair for social functions and relationships previously damaged by social and psychological challenges stemming from AUD and a return to a previous state.

It has been found that AUD sufferers who consumed less alcohol had improved physical functioning, participated in Alcoholics Anonymous (AA), had high levels of family and other social support, and had fewer emotional conflicts with their family members. Some reported relatively high levels of life satisfaction, which could be considered a proxy for QoL $[12,18]$. Many South Korean studies on AUD have found that social support $[19,20]$, depression, and anxiety [21] are significant determinants for QoL. Depression is a common accompanying disease in people with alcohol-related disorders and is an obstacle to recovery [22, 23]. By contrast, social support, defined as any positive help [24] obtained from any of an AUD sufferer's relationships, is a useful resource for adaptation at a preventative and therapeutic level, reduces the perception of stress, and relieves the pathological symptoms that result from it [25]. Taken together with the results of previous studies $[26,27]$ that indicate the association of social support with reduction in mental health problems such as depression and suicidal behavior, the importance of social support is evident. However, these studies have largely considered individual factors, such as psychological variables or drinking behaviors that affect QoL. Consequently, these studies have been limited due to their omission of antecedent factors, such as socioeconomic variables, that may affect depression in people with AUD or the social support they enjoy.

In addition to individual psychological factors, AUD is associated with important life events and problems, such as job dismissals, unstable employment, housing difficulties, poor relationships with family and others, and social deprivation $[6,7,28]$. These problems may appear either as causes or as outcomes of addiction. Recent studies on the association between drinking problems and the characteristics of vulnerable groups found that rates of alcohol abuse and dependence are higher among individuals who receive public assistance benefits, are unemployed, or have lower incomes [28].

Studies in South Korea have found that socioeconomic factors are related to problematic drinking in the general population [29-31]. Financial factors and social support also influence the state of mental health in certain socially vulnerable populations [32, 33]. However, empirical research on to the influence of socioeconomic difficulties or deprivation on the recovery process of people with AUD in South Korea has been limited.

The assessment of QoL should include the evaluation of complex relationships among aspects of physical health, psychological states, personal faith, social relationships, and the environment. For this reason, this study went beyond psychological factors and drinking behaviors in its assessment of QoL among people with AUD. The influence of socioeconomic factors and social support (indicative of social relationships), were investigated, in addition to the influence of psychological factors (e.g., depression) on QoL, using a variety of pathways. The analysis and verification of relevant path models allowed this study to develop an understanding of the recovery of patients with AUD and improvements to their QoL within a broad social context. Specifically, we examined whether socioeconomic factors were antecedents that affect the relationship between social support and depression, as well as exploring whether social support and depression mediate the relationship between socioeconomic factors and QoL in AUD.

\section{Methods}

\section{Study model}

The research model adopted presented how explanatory variables, such as income level, work experience, and possession of a home, affect QoL through the mediating variables of social support and depression. The study model is shown in Fig. 1.

\section{Sample}

This study targeted men and women between the ages of 19 and 65 who were registered at 28 hospitals and 34 addiction management centers and were diagnosed as having AUD in the year before the study began. The 


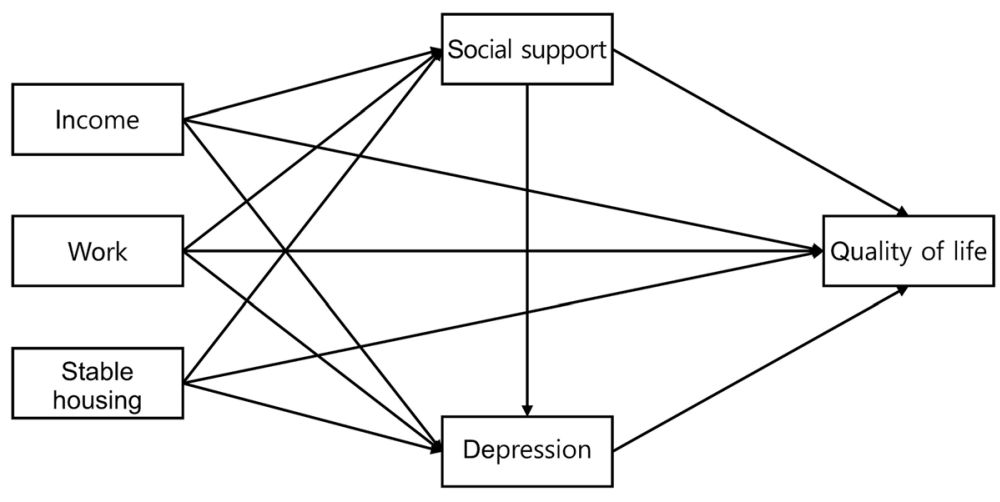

Control variable : Sex, Age, Marital status, Religion

Fig. 1 Research Model. The figure depicts the research model of the study, which examines the mediating effects of social support and depression between the socioeconomic resources and QoL among alcohol use disorder patients

clinicians who participated in the study employed the DSM-5 and AUDIT scales to obtain their diagnoses. A survey was conducted using one-to-one interviews and self-reporting.

The exclusion criteria were the following: being deemed unfit for the study because of severe physical illness, having a severe cognitive impairment that interfered with the perception of reality, or being otherwise assessed by clinicians as an inappropriate subject for the study. Of the 440 people who participated, 36 did not reply to more than half of the questions or were judged by the clinician to have given false responses and their data were excluded from the analysis after discussion among the researchers. Ultimately, 404 people were included in the analysis. This study was approved by the Public Institutional Review Board designated by Ministry of Health and Welfare (P01-201603-21-001).

\section{Main variables}

\section{QoL}

This study used the Korean version of the World Health Organization Quality of Life Scale-Abbreviated Version (K-WHOQOL-BREF), a subjective measure of QoL over the previous two weeks with 26 questions. The selfreport questionnaire includes four domains (physical health, psychological states, social relationships, and living environment), and the subscales for each domain are used to evaluate overall QoL [34]. The scores for each domain and the mean of scores for all questions within each domain were multiplied by four. The total score was the sum of the scores for each domain, and higher total scores indicated higher overall QoL.

\section{Work}

In this study, work describes whether a participant had held a stable job for at least 3 months over the past year, working at least 5 days per week. Response options were $0=$ no and $1=$ yes.

\section{Housing}

Housing was an indicator that a participant had a stable residence. Response options were $0=$ no and $1=$ yes.

\section{Income}

Income was an ordinal variable measuring average monthly household income. Response options were $0=$ less than KRW 1,000,000, $1=\mathrm{KRW} 1,000,000$ to less than $3,000,000,2=\mathrm{KRW} 3,000,000$ to $5,000,000$, and $3=$ more than KRW 5,000,000.

\section{Social support}

The Perceived Social Support Scale developed by Blumenthal et al. [35] was used to measure this variable. This scale includes 12 items: perceived social support from family (four questions), friends (four questions), and significant others (four questions), with response options given on a five-point Likert-type scale where $1=$ strongly disagree to $5=$ strongly agree. Higher total scores indicate higher perceived social support.

\section{Statistical analysis}

The data were analyzed using SPSS 25 and AMOS 25.0, as follows. First, the participants' demographic characteristics were assessed using descriptive statistics. Second, structural equation modeling and path analysis were performed to examine the relationships among housing, work, income, and QoL. Last, a bootstrap analysis was performed to test the mediating effects of social support and depression. Structural equation modeling, which includes statistical techniques for controlling measurement errors, facilitating the use of parameters, and enabling the statistical evaluation of the theoretical 
model, was considered appropriate for validation of the study model [36].

\section{Results}

\section{Demographic characteristics}

As shown in Table 1, the sample was $80 \%$ male, $78 \%$ unmarried, and $64.4 \%$ without religious affiliation. Slightly more participants $(57.2 \%)$ had held a stable job for at least 3 months in the past year, working at least 5 days per week, than those who did not; $83.7 \%$ reported stable residence, and $52.5 \%$ reported monthly family incomes of less than KRW $1,000,000,24.5 \%$ of KRW 1,000,000 to less than $3,000,000,12.9 \%$ of KRW 3,000,000 to less than $5,000,000$, and $10.01 \%$ of more than KRW 5,000,000. The participants' mean age was 51.2 years.

\section{Correlation analysis}

The correlation coefficients for the major variables used in the study ranged from .009 to .658 . Because the coefficients were less than 0.7 , they were considered to have met the criteria for multicollinearity diagnostic (see Additional file 1) [37].

\section{Path analysis}

Table 2 presents the results of the path analysis model, which had an appropriate goodness-of-fit (NIB $=.998$, $\mathrm{RAFI}=.974, \mathrm{CFI}=1.000$, and $\mathrm{MESA}=.000)$. Income $(\beta=.297, p<.001)$, stable employment $(\beta=.131, p<.01)$, and stable residence $(\beta=.091, p<.05)$ were significantly and positively related to social support. Second, income, stable employment, and stable residence had no significant relationship to depression. However, social support did have a significant negative relationship to depression $(\beta=-.172, p<.001)$. Third, income directly influenced QoL $(\beta=.148, p<.001)$. The influences of stable employment and residence were not statistically significant. Path analysis found that social support $(\beta=.331$, $p<.001)$ and depression $(\beta=-.477, p<.001)$ had significant mediating effects on QoL. Patients with AUD who reported higher QoL had higher scores for social support and lower ones for depression. In brief, AUD patients' incomes, employment, and housing were found to influence their QoL through the mediation of social support. Although socioeconomic resources did not directly influence QoL, they had statistically significant influences on depression through social support, which, in turn, influenced QoL.

\section{Bootstrapping analysis}

Bootstrapping was performed to investigate the mediating effects of social support and depression on the relationship between QoL and socioeconomic resources (i.e., income, stable employment, and stable residence) (Table 3). Income (.317) exerted the most significant influence on QoL, followed by stable employment (.115) and stable residence (.098). Moreover, income (.169) and stable residence (.088) had significant indirect effects on QoL. The total effect of social support on QoL was .545, and its indirect effect was significant $(p<.01)$.

Table 1 Socio-demographic characteristics: Alcohol use disorder patients ( $n=440)$

\begin{tabular}{|c|c|c|c|}
\hline Variable & & Frequency & $\%$ \\
\hline \multirow[t]{2}{*}{ Sex } & Male & 323 & 80.0 \\
\hline & Female & 81 & 20.0 \\
\hline \multirow[t]{2}{*}{ Marital status } & Yes & 89 & 22.0 \\
\hline & No & 315 & 78.0 \\
\hline \multirow[t]{2}{*}{ Religion } & Yes & 260 & 64.4 \\
\hline & No & 144 & 35.6 \\
\hline \multirow[t]{2}{*}{ Stable employment } & Yes & 173 & 42.8 \\
\hline & No & 231 & 57.2 \\
\hline \multirow[t]{2}{*}{ Housing } & Yes & 338 & 83.7 \\
\hline & No & 66 & 16.3 \\
\hline \multirow[t]{4}{*}{ Income } & less than KRW 1,000,000 & 212 & 52.5 \\
\hline & KRW $1,000,000$ to less than $3,000,000$ & 99 & 24.5 \\
\hline & KRW $3,000,000$ to $5,000,000$ & 52 & 12.9 \\
\hline & more than KRW 5,000,000 & 41 & 10.1 \\
\hline \multirow[t]{2}{*}{ Total } & & 404 & 100.0 \\
\hline & & Mean & Standard deviation \\
\hline Age & & 51.16 & 9.65 \\
\hline
\end{tabular}

The table represents the sociodemographic characteristics of the sample used in the study 
Table 2 Path analysis results: The mediating effects of social support and depression

\begin{tabular}{|c|c|c|c|c|c|c|}
\hline Predictor & & Outcome & $\beta$ & $B$ & S.E. & C.R. \\
\hline Income & $--->$ & Social support & $0.297^{* * *}$ & 5.700 & 1.009 & 5.652 \\
\hline Stable employment & $--->$ & & $0.131^{* *}$ & 5.126 & 1.865 & 2.749 \\
\hline Residence & $-->$ & & $0.091^{*}$ & 4.801 & 2.404 & 1.997 \\
\hline Income & $--->$ & Depression & -0.014 & -0.111 & 0.424 & -0.261 \\
\hline Stable employment & $--->$ & & 0.045 & 0.708 & 0.762 & 0.929 \\
\hline Residence & $-->$ & & -0.08 & -1.699 & 0.978 & -1.737 \\
\hline Social support & $--->$ & & $-0.172^{* * *}$ & -0.181 & 0.02 & -8.983 \\
\hline Income & $--->$ & QoL & $0.148^{* * *}$ & 1.736 & 0.433 & 4.008 \\
\hline Stable employment & $-->$ & & 0.065 & 1.551 & 0.833 & 1.861 \\
\hline Residence & $--->$ & & 0.010 & 0.311 & 1.061 & 0.293 \\
\hline Depression & $--->$ & & $-0.477^{* * *}$ & -0.722 & 0.053 & -13.581 \\
\hline Social support & $--->$ & & $0.331^{* * *}$ & 0.203 & 0.024 & 8.559 \\
\hline Sex & $--->$ & Social support & 0.071 & 3.441 & 2.146 & 1.603 \\
\hline Age & $--->$ & & $0.093^{* *}$ & -0.249 & 0.094 & -2.663 \\
\hline Marital status & $--->$ & & -0.095 & 4.341 & 2.366 & 1.835 \\
\hline Religion & $--->$ & & $-0.124^{*}$ & -3.833 & 1.769 & -2.168 \\
\hline Sex & $--->$ & Depression & -0.448 & 0.316 & 0.872 & 0.363 \\
\hline Age & $--->$ & & $0.016^{* * *}$ & -0.14 & 0.038 & -3.668 \\
\hline Marital status & $--->$ & & -0.045 & -0.856 & 0.962 & -0.89 \\
\hline Religion & $-->$ & & $0.102^{*}$ & 1.667 & 0.72 & 2.316 \\
\hline
\end{tabular}

The table represents results of path analysis that analyzed the mediating effects of social support and depression between the socioeconomic resources and QoL among alcohol use disorder patients.

$B$, non-standardized coefficients; $\beta$, standardized coefficients; $C R$, critical ratio.

$\mathrm{X}^{2}=2.043, \mathrm{df}=4, p>.05(p=.728)$.

$\mathrm{NFI}=.998, \mathrm{RFI}=.974, \mathrm{CFI}=1.000, \mathrm{RMSEA}=.000$.

${ }^{* * *} p<.001,{ }^{* *} p<.01,{ }^{*} p<.05$

\section{Discussion}

AUD causes social and employment dysfunctions, leading to a range of problems in sufferers' families and employment [38]. Due to its high relapse rate, recovery from AUD requires continuous management throughout all aspects of life that goes beyond a focus on treatment completion alone. The concept of addiction recovery has expanded from reducing alcohol consumption to making overall improvements in health, social relationships, and QoL [14]. In particular, because AUD is a risk factor for lower QoL [16], changes in the QoL of people with AUD are relevant treatment targets. In other words, recovery from AUD could be enhanced by a focus on improving patient QoL. In turn, the hope of a better life could incentivize and motivate patient recovery [39]. Therefore, improving QoL is recognized as an important therapeutic goal [12, 13]. Psychological factors, significant relationships, and socioeconomic factors have influence on the lives of people with AUD. Socioeconomic factors, such as income, residence, and employment, might increase the risk of addiction and adversely influence people with AUD [15, 40, 41]. This study expanded the scope of previous studies and explored the ways that socioeconomic resources influence the QoL of patients with AUD through specific pathways.

Table 3 Bootstrapping analysis for validation of effectiveness of final path analysis results

\begin{tabular}{|c|c|c|c|c|c|c|}
\hline Predictor & & Outcome & Total effect & Direct effect & Indirect effect & Indirect confidence interval \\
\hline Income & $\rightarrow$ & QoL & .317 & .148 & .169 & $.105-.224^{* *}$ \\
\hline Stable employment & & & .115 & .065 & .050 & $.000-.104$ \\
\hline Residence & & & .098 & .010 & .088 & $.031-.145^{*}$ \\
\hline Social support & & & .545 & .331 & .214 & $.170-.251^{* *}$ \\
\hline
\end{tabular}

The table describes the results of bootstrapping analysis of the final path analysis, which examined the effect of predictor variables (income, stables employment, residence, and social support) on QoL among alcohol use disorder patients.

${ }^{* * *} p<.001,{ }^{* *} p<.01,{ }^{*} p<.05$ 
This study's findings demonstrate that having higher income, stable employment, and a stable residence increased social support for patients with AUD. Furthermore, as expected, patients who perceived higher levels of social support had lower scores for depression and higher ones for QoL. When the size of the influence was measured through bootstrapping, income level, work experience, and possession of a house were among the socioeconomic resources that most affected QoL of those with AUD; furthermore, income level and possession of a house were shown to have statistically significant indirect effects on QoL through social support and depression.

The results of the present study support previous findings showing that low social support for patients with AUD predicts lower QoL [18, 42]. Depression also predicted QoL in AUD patients. This study confirmed the findings of a previous study [15] that people with AUD and co-morbid depressive symptoms had a higher risk for relapse and a lower QoL.

Qualitative studies on the difficulties of recovery for patients from economically vulnerable groups who had AUD found that the physical and mental states that accompany addiction tend to interfere with the establishment of financial independence, which hinders recovery process. In particular, the cost of transportation to AA meetings or treatment centers could be burdensome for low-income patients. A study of QoL in people treated for addiction in Singapore found that people addicted to gambling reported a lower QoL than those who had other addictions, suggesting that financial and material hardships are significant adverse factors for QoL [39].

The study findings imply that the recovery from unstable living conditions caused by the loss of socioeconomic abilities by people with AUD will help restore QoL. Social support is a very important factor for QoL in people with AUD, either in itself or as a mediating variable. Social support can be obtained from socioeconomic resources, suggesting that it can also affect depression and improve QoL in sufferers from AUD. To facilitate recovery, addiction treatment must include intervention that takes into account the life functions of individuals whose social support has been damaged by the impact of AUD as well as the impact of a possible coexisting condition of depression. Study findings showed that socioeconomic resources did not directly influence depression, but indirectly through social support. This indicates that those suffering from AUD experienced depression not directly because they lacked socioeconomic resources, but because of the breakdown in social functions and social support resulting from lack of socioeconomic resources.

One of the limitations of this study is that the sample consists of those in treatment with a formal AUD diagnosis. Statistics show that less than 10\% of those who need treatment for AUD actually receive treatment [43]. Therefore, the results should be interpreted with care when applying to people with alcohol problems in general. Second, because the study adopts a crosssectional design, there is a predictive limitation to the relationship between socioeconomic resources and QoL. Without longitudinal data, it is difficult to establish a cause-and-effect relationship between variables.

\section{Conclusions}

This study confirmed that socioeconomic resources directly relate to QoL, as well as indirectly through social support. In addition, socioeconomic resources were found to indirectly influence depression through social support, which, in turn, influenced QoL. Lack of socioeconomic resources could cause or be caused by addiction. Many previous studies have suggested that socioeconomically vulnerable populations are more vulnerable to addiction. Therefore, although addiction interventions must improve the level of social support for individuals and decrease depressive symptoms, ways to increase socioeconomic resources should be considered at the same time.

The results of this study demonstrate that in relation to QoL for people with AUD and their return to normal functioning and ultimate recovery, functional recovery in socioeconomic dimensions, including physical, occupational, and income factors, has a large impact on both their social support and depression, and these factors ultimately contribute to recovery, which was considered to be a return to a previous normal state that had been lost due to AUD. In short, recovery and the return to a healthy life should be considered in relation to the restoration of social functions and relationships through increasing socioeconomic resources.

\section{Supplementary information}

Supplementary information accompanies this paper at https://doi.org/10. 1186/s13011-020-00258-6.

Additional file 1. Correlations between major variables. The table

describes correlation coefficients between major variables.

\section{Abbreviations}

AA: Alcoholics Anonymous; AUD: Alcohol use disorder; AUDIT: Alcohol use disorders identification test; K-WHOQOL-BREF: Korean version of the World Health Organization Quality of Life Scale- Brief; QoL: Quality of life

\section{Acknowledgements}

We thank all the people involved in the data collection process.

\section{Authors' contributions}

S Chung and SB Lee wrote and revised the manuscript. SB Lee analyzed the data and interpreted the results. JS Seo and WM Chung contributed to the data collection. IH Park revised the manuscript. All authors read and approved the final manuscript. 


\section{Funding}

This study was supported by a grant from the Korean Mental Health Technology R\&D Project, Ministry of Health \& Welfare, Republic of Korea (HM15C-1242-010017). The funding agency had no role in the study design, the collection, analysis, or interpretation of data, the writing of the report, or the decision to submit the article for publication.

\section{Availability of data and materials}

The datasets used and analyzed during the current study are available from the corresponding author on reasonable request.

\section{Ethics approval and consent to participate}

This study received approval from the Public Institutional Review Board designated by Ministry of Health and Welfare (P01-201603-21-001). All study participants provided informed consent.

\section{Consent for publication}

Not applicable.

\section{Competing interests}

The authors declare that they have no competing interests.

\section{Author details}

'Department of Social Welfare, Chung-Ang University, 84 Heuksuk-Ro, Dongjak-Gu, Seoul, South Korea. ${ }^{2}$ Department of Psychiatry, School of Medicine, Konkuk University, Chung-ju, South Korea. ${ }^{3}$ Department of Social Welfare, Ewha Womans University, Seoul, South Korea. ${ }^{4}$ Department of Psychiatry and Behavioral Neurosciences, Catholic Kwandong University International Saint Mary's Hospital, Incheon, South Korea.

\section{Received: 14 June 2019 Accepted: 10 February 2020} Published online: 17 February 2020

\section{References}

1. Hong JP, Lee DW, Ham BJ, Lee SH, Sung SJ, Yoon T. The survey of mental disorders in Korea 2016. Seoul, South Korea: Ministry of Health and Welfare; 2017.

2. Lee HK, Lee MS, Ki SW, Choi SW, Joe KH, Park A, et al. Developing therapeutic framework for treatment of alcoholism - focused on Seoul alcohol action plan. J Korean Assoc Soc Psychiatry. 2007;12(2):57-67.

3. Kwak CW. Income inequality and mortality among patients with alcohol use disorder in South Korea. [master's thesis]. Seoul, Korea: Yonsei University; 2017.

4. Fletcher K. Couple therapy treatments for substance use disorders: a systematic review. J Soc Work Pract Addict. 2013;13(4):327-52.

5. Petersen $\mathrm{CL}$, Zettle RD. Treating inpatients with comorbid depression and alcohol use disorders: a comparison of acceptance and commitment therapy versus treatment as usual. Psychol Rec. 2009;59(4):521-36.

6. Woo JH. A study of stress and resilience alcoholic: focused on the mediating effect of social support. Ment Health Soc Work. 2015:43(3):279-303.

7. Dethier M, Counerotte C, Blairy S. Marital satisfaction in couples with an alcoholic husband. J Fam Violence. 2011;26(2):151-62.

8. Kweon $Y$, Lee $H$, Lee J, Lee C. A follow up study of alcoholic inpatients after alcoholism treatment program. J Korean Acad Addiction Psychiatry. 2002;6: 114-9.

9. Lee SB, Cho SE, Chung S, Lee HK, Joe KH, Jung WM, et al. Factors affecting the maintenance of clinical services among Korean patients with alcohol use disorder. J Korean Acad Addiction Psychiatry. 2018;22(2):64-9.

10. Daley DC. Relapse prevention with substance abusers: clinical issues and myths. Soc Work. 1987;32(2):138-42.

11. Hogan F. President's new freedom commission on mental Health, achieving the promise: transforming mental health care in America. Final report. Rockville, MD: Substance Abuse and Mental Health Services Administration; 2003.

12. Donovan D, Mattson ME, Cisler RA, Longabaugh R, Zweben A. Quality of life as an outcome measure in alcoholism treatment research. J Stud Alcohol Suppl. 2005;15:119-39.

13. Hambley J, Arbour S, Sivagnanasundaram L. Comparing outcomes for alcohol and drug abuse clients: a 6-month follow-up of clients who completed a residential treatment programme. J Subst Use. 2010;15(3): 184-200.
14. Nower $L$, Blaszczynski A. Recovery in pathological gambling: an imprecise concept. Subst Use Misuse. 2008;43(12-13):1844-64.

15. Saatcioglu O, Yapici A, Cakmak D. Quality of life, depression, and anxiety in alcohol dependence. Drug Alcohol Rev. 2008;27(1):83-90.

16. Foster JH, Marshall EJ, Peters TJ. Application of a quality of life measure, the life situation survey (LSS), to alcohol-dependent subjects in relapse and remission. Alcohol Clin Exp Res. 2000;24(11):1687-92.

17. Yoon MS, Chung YC, Lee JS, Lee BH, Cho HC. Effects of family support on quality of life among alcohol dependent patients: moderating effect of abstinence self-efficacy. J Korean Neuropsychiatr Assoc. 2012;51(5):277-84.

18. Foster JH, Powell JE, Marshall EJ, Peters TJ. Quality of life in alcoholdependent subjects-a review. Qual Life Res. 1999;8(3):255-61.

19. Lee B. The effects of social support on life satisfaction of alcoholics. Ment Health Soc Work. 2006;22:33-57.

20. Yoon MS, Kim NH. Mediating effects of social support on the relationship between motivation to change and quality of life among alcoholics. Health Soc Welfare Rev. 2015:35(1):110-35.

21. Choi SW, Na RH, Kim HO, Choi SB, Choi YS. The relationship between quality of life and psycho-socio-spiritual characteristics in male patients with alcohol dependence. J Korean Neuropsychiatr Assoc. 2006;45(5):459-67.

22. Lee EH. The effect of alcoholics' depression on suicidal ideation - the mediating effect of social support. J Digit Converg. 2019;17(2):423-31.

23. Hakko HP, Koponen KV. Alcohol-related suicides in victims with a history of hospital-treated depression. Am J Addict. 2005;14:455-63.

24. Park JW. The development of Social Support Scale. [doctoral dissertation] Seoul, Korea, Yonsei University, 1985.

25. Lee KJ. Stress, social support, and behavior problems of adolescents. [doctoral dissertation] Gwangju, Korea, Chonnam University, 1997.

26. Park K. The moderating effects of problem-solving and social support on the relationship between child abuse and suicidal ideation in adolescents. Korean J School Psychol. 2005;2(2):131-47.

27. Eom TW. Elderly suicide and its related factors: focused on the role of social support and mastery in the effects of hopelessness and depression on suicidal ideation. Korean J Soc Welfare. 2007;59(2):355-79.

28. Chung S, Kim YS, Song JH, Lee SB, Lee SY. Socioeconomic determinants and effect of poverty and inequality on alcohol consumption: practice and policy strategies for vulnerable population. Policy report. Korean Ministry of Health and Welfare; 2015.

29. Chung S, Lee S. Poverty and perceived income inequality and changes in growth trajectory of problem drinking. Korean J Health Edu Promotion. 2015;32(5):43-51.

30. Lee S, Chung S, Lee S. Economic deprivation and problem drinking: mediating effect of perceived income inequality and depressive mood. Alcohol Health Behav Res. 2016;17(2):79-91.

31. Lee M, Chung S. The causal relationship between socioeconomic deprivation and problem drinking-a comparative analysis of age. Ment Health Soc Work. 2018:46(3):5-33.

32. Eom TW. The effects of self-efficacy and social support in the relationship between economic stress and depression of the indigent population. Ment Health Soc Work. 2008;28(4):36-66.

33. Kim YS, Kwak JY. The effects of life-events stress, social support, and family cohesion on depression of female heads in poverty: focused on women with children under 18 in Seoul. Seoul Stud. 2010;11(1):161-79.

34. Min SK, Lee Cl, Kim Kl, Suh SY, Kim DK. Development of Korean version of WHO quality of life scale abbreviated version (WHOQOL-BREF). J Korean Neuropsychiatr Assoc. 2000;39(3):571-9.

35. Blumenthal JA, Burg MM, Barefoot J, Williams RB, Haney T, Zimet G. Social support, type A behavior, and coronary artery disease. Psychosom Med. 1987:49:331-40.

36. Byrne BM. Structural equation modeling with AMOS. Basic concepts, applications, and programming. New Jersey: Lawrence Erlbaum Associates; 2001.

37. Berry WD, Feldman S. Multiple regression in practice: quantitative applications in the social sciences. Thousand Oaks: SAGE Publications; 1985.

38. Dawson DA, Li TK, Chou SP, Grant BF. Transitions in and out of alcohol use disorders: their associations with conditional changes in quality of life over a 3-year follow-up interval. Alcohol Alcohol. 2008;44(1):84-92.

39. Manning V, Gomez B, Guo S, Low YD, Koh PK, Wong KE. An exploration of quality of life and its predictors in patients with addictive disorders: gambling, alcohol and drugs. Int J Ment Health Addict. 2012;10(4):551-62.

40. Burke TR. The economic impact of alcohol abuse and alcoholism. Public Health Rep. 1988;103(6):564-8. 
41. Romeis JC, Waterman BR, Scherrer JF, Goldberg J, Eisen SA, Heath AC, et al. The impact of sociodemographics, comorbidity and symptom recency on health-related quality of life in alcoholics. J Stud Alcohol. 1999;60(5):653-62.

42. Morgan TJ, Morgenstern J, Blanchard KA, Labouvie E, Bux DA. Health-related quality of life for adults participating in outpatient substance abuse treatment. Am J Addict. 2003;12(3):198-210.

43. National Institute on Alcohol abuse and Alcoholism. Alcohol facts and statistics. 2019. https://www.niaaa.nih.gov/publications/brochures-and-factsheets/alcohol-facts-and-statistics. Accessed 20 Jan 2020.

\section{Publisher's Note}

Springer Nature remains neutral with regard to jurisdictional claims in published maps and institutional affiliations.

Ready to submit your research? Choose BMC and benefit from:

- fast, convenient online submission

- thorough peer review by experienced researchers in your field

- rapid publication on acceptance

- support for research data, including large and complex data types

- gold Open Access which fosters wider collaboration and increased citations

- maximum visibility for your research: over $100 \mathrm{M}$ website views per year

At $B M C$, research is always in progress.

Learn more biomedcentral.com/submissions 